\title{
Meio ambiente: gestão pública e educomunicação
}

Ismar de Oliveira Soares

Professor titular da ECA/USP, coordenador da Licenciatura em Educomunicação da ECA-USP.

E-mail: ismarolive@yahoo.com

Resumo: $\mathrm{O}$ artigo traça uma análise de três obras voltadas ao tema da gestão pública do meio ambiente e educomunicação, permitindo identificar uma clara relação entre políticas públicas para o meio ambiente e educomunicação socioambiental - fato que não pode passar despercebido pelos estudiosos da inter-relação comunicação/ educação no Brasil.

Palavras-chave: Educomunicação, gestão ambiental, meio ambiente, políticas públicas.
Abstract: The article analyzes three works on the topic of public management of the environment and media education, identifying a clear connection between public policies for the environment and socio-environmental media education - a fact that cannot go unnoticed by those who study the interrelation between communication and education in Brazil.

Keywords: Media Education, environmental management, environment, public policies.

\section{A EDUCOMUNICAÇÃO NAS INTERFACES}

O livro Gestão pública do ambiente e educação ambiental: caminhos e interfaces ${ }^{1}$, organizado por Carlos Frederico Loureiro - coordenador do Laboratório de Investigações em Educação, Ambiente e Sociedade - LIEAS-UFRJ -, trabalha, ao longo de seus seis artigos, uma aproximação possível entre o discurso do estado e o mundo da educação ambiental. A obra dirige-se aos gestores públicos enquanto sujeitos de processos de aprendizagem relacionados às condições epistemológicas e políticas de uma gestão ambiental que se espera voltada à justiça social e ao respeito à diversidade biológica e cultural, assim como à emancipação humana e à sustentabilidade ecossistêmica.

O livro tem início com o relato da história das políticas públicas federais sobre educação ambiental, que teve seu começo com a instituição da Secretaria Especial do Meio Ambiente, no Ministério do Interior (1973), e seu momento de expansão democratizadora a partir de 2004, quando o MMA promoveu o ambicioso plano de transformar 180 milhões de brasileiros em educadores ambientais através dos "Coletivos Educadores" - organizando em consequência, em Brasília, a I Oficina de Comunicação e Educação Ambiental, que teve como uma de suas metas implantar um programa de educomunicação socioambiental. Este conceito acaba sendo consolidado no documento que instituiu a Estratégia Nacional de Comunicação e Educação Ambiental - ENCEA, em 2011, estabelecido em consenso pelo Departamento de Educação Ambiental, o

1. LOUREIRO, Carlos Frederico (org.). Gestão pública do ambiente e educação ambiental: caminhos e interfaces. São Paulo: RiMa Editora, 2012. 
comunicação \& educação • Ano XVII • número 2 • jul/dez 2012

Departamento de Áreas Protegidas do Ministério do Meio Ambiente (MMA) e o Instituto Chico Mendes de Conservação da Biodiversidade - ICMBio (www. icmbio.gov.br/portal/). O autor considera o documento como um recomeço, levando em conta o esvaziamento institucional que a educação ambiental vinha sofrendo ao longo das últimas décadas, devido a pressões de setores econômicos e políticos pelo desmantelamento da vigilância do MMA sobre as áreas de preservação no país.

A obra segue numa escalada de aprofundamento teórico-histórico, com capítulos como "Educação ambiental e gestão participativa de unidades de conservação", de Cláudia Cunha e Carlos Loureiro; "Gestão pública das águas e educação ambiental", de Gustavo Gomes e C. Loureiro; "Direito das águas e racismo ambiental", de Júlio Cesar da Rocha; e "Por uma avaliação democrática de políticas, programas e projetos de educação ambiental”, de Cláudia Lopes Pocho. Finaliza com o capítulo "Aproximações sobre os discursos do Estado e do empresariado: os exemplos de sustentabilidade e da responsabilidade social", de Leonardo Kaplan, Mônica Serrão, Rodrigo Lamosa e Carlos Loureiro.

Este derradeiro capítulo converte-se num interessante estudo sobre "a privatização da cidadania e a pedagogia das hegemonias", consolidadas pelo capitalismo global e pelo neoliberalismo. Distingue que, nessa luta - cenário para o próprio esvaziamento da educação ambiental por parte do poder público - estão, de um lado, o Estado que passa a ser o grande inimigo, contra quem o mundo empresarial, sedento de total liberdade para agir e gerenciar o meio ambiente, investe tanto, e do outro lado a esfera das organizações da sociedade civil, que propõem o conceito de "público não estatal", mantendo as privatizações dentro da ideia de uma sociedade de bem-estar social e não mais de um Estado de bem-estar social. Os autores lembram que os empresários, considerados "vilões da ecologia" até os anos de 1980, passaram a apropriar-se ideologicamente de um discurso pelo qual se apresentam como "amigos da natureza" e "promotores privilegiados do desenvolvimento sustentável". Ao final, após constatar o avanço quantitativo da educação ambiental nas escolas brasileiras (94\% delas afirmam prever alguma atividade na área), bem como registrar o esforço dos setores organizados - tanto do empresariado (em torno de ações de responsabilidade social) quanto dos movimentos sociais (o trabalho das ONGs envolvidas com a prática ambientalista) -, o capítulo preocupa-se com o tipo de educação promovida nas escolas, em muitos dos casos, a partir do apoio empresarial. O texto lembra, a título de exemplo, dados de uma pesquisa de mestrado (defendida na UFRJ) que identificou que nenhum dos projetos empresariais de educação ambiental desenvolvidos em $43 \%$ das escolas de Teresópolis, no Rio Janeiro, em 2010, dialogava com os pressupostos e os temas propostos pelo MMA para a educação ambiental no país. Mais assustador, para eles, é o programa que a Associação Brasileira de Agronegócios (ABAG) vem desenvolvendo em escolas do estado de São Paulo desde 2001.

Pela abrangente temática desenvolvida, o livro é absolutamente imprescindível num debate sobre a educação ambiental no Brasil no início da segunda década do século XXI. 


\section{A EDUCOMUNICAÇÃO NAS CURVAS DO RIO SÃO FRANCISCO}

A presença do Estado, como promotor de uma educação ambiental universalizada e participativa, ganha reforço no livro coordenado por Franklin Paula Junior e Suraya Modaelli, tendo como título Política de águas e educação ambiental: processos dialógicos e formativos em planejamento $e$ gestão de recursos hídricos ${ }^{2}$.

A importância do livro e dos temas tratados reside no fato de o Plano Nacional de Recursos Hídricos (PNRH) ter sido elaborado a partir de consultas que envolveram, diretamente, mais de 7 mil atores da gestão hídrica e ambiental do país. Em consequência, segundo a Ministra Isabella Teixeira, que introduz a obra, o plano

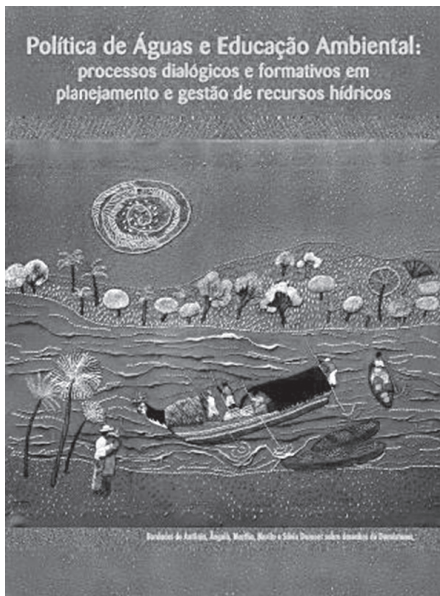
agrega valores para a consolidação de uma governança democrática e sustentável de nossas águas e estabelece, como um de seus objetivos centrais, uma educação socioambiental de caráter participativo e compartilhado, cuja meta mais abrangente é a "percepção da conservação da água como valor socioambiental relevante".

Na verdade, o livro deve ser considerado, em si mesmo, como uma rica fonte para os estudiosos da gestão e avaliação de projetos no campo da gestão comunicativa. Destina todo o primeiro capítulo justamente à definição dos parâmetros metodológicos para o tratamento das atividades dialógicas na área da educação ambiental, postura defendida pela educomunicação.

O conceito é explicitamente referido por Franklin Paula Junior no capítulo introdutório da obra, quando lembra, à p. 39, que "cabe à educomunicação chegar a cada segmento da sociedade, para instigar novas reflexões e fazer dessas reflexões peças de comunicação para divulgar outras perspectivas de necessidades e de desejos em relação à água e à sociedade como um todo”. E ajuíza: "Parece-me uma opção acertada e que sugere apoio de políticas públicas comprometidas com uma educação ambiental transformadora”. No entanto, é no capítulo 4, sobre "Saberes e cuidados em ação", que o tema da educomunicação é prestigiado com os relatos de Ricardo Tezini Minoti e Andréa Carestiato, no subtítulo "O projeto Nas Ondas do São Francisco e a gestão ambiental integrada e participativa".

O texto lembra que "Nas Ondas, promovido entre dezembro de 2009 e junho de 2010, consistia na veiculação de spots (peças radiofônicas), produzidos pelas próprias comunidades da Bacia Hidrográfica do São Francisco, nas rádios que cobrem aquela região" (p. 103). Lembra, ainda, o documento que esta foi uma das primeiras iniciativas em Educação Ambiental (EA) do MMA voltadas à promoção da educomunicação socioambiental.
2. PAULA JUNIOR, Franklin \& MODAELLI, Suraya. Política de águas e educação ambiental: processos dialógicos e formativos em planejamento e gestão de recursos hídricos. Brasília: Ministério do Meio Ambiente, 2011. 
comunicação \& educação • Ano XVII • número 2 • jul/dez 2012

O texto esclarece também que o projeto NOSF tinha como principal objetivo dar voz às comunidades da Bacia do Rio São Francisco, contribuindo com a tomada de consciência quanto à importância de sua participação nos processos locais e regionais de gestão ambiental. Para tanto, incluiu uma parceria com rádios, movimentos sociais, sociedade civil organizada e órgãos governamentais para a produção de spots radiofônicos, promovendo oficinas de avaliação para a definição de indicadores de efetividade de ações socioambientais empreendidas, além de acompanhar e monitorar a rede social dos participantes e parceiros.

A experiência passou a ser vista, pelo próprio MMA, como um caso a ser estudado dentro das políticas de ação emanadas pelas Diretrizes para a Estratégia Nacional de Comunicação e Educação Ambiental em Unidades de Conservação da ENCEA ${ }^{3}$.

\section{EDUCAR NO AMBIENTE}

Vânia Maria Nunes dos Santos, socióloga, mestre em educação pela Faculdade de Educação da USP (FEUSP) e doutora em geociência pela Universidade Estadual de Campinas (UNICAMP), é a autora do livro Educar no ambiente: construção do olhar geocientífico e cidadania ${ }^{4}$. Sua preocupação volta-se expressamente para o ensino em geociências, envolvendo a relação deste campo com a formação de professores e a construção do "olhar geocientífico" na escola.

A obra - vencedora do Prêmio CAPES de tese no ano de 2007 - apresenta-se como o coroamento

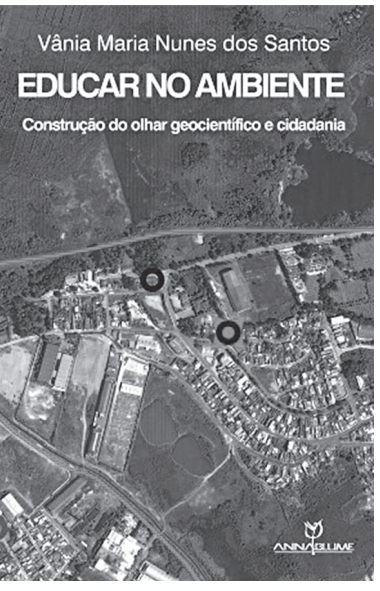
de um projeto de educação ambiental no município de Guarulhos, São Paulo, denominado "Guarulhos: saneamento ambiental e qualidade de vida", com início em 2001 e que contou, entre os agentes envolvidos, com professores e alunos de 180 escolas, além das comunidades do entorno - tendo alcançado dialogar com um público de aproximadamente 170 mil pessoas.

3. ENCEA - Estratégia Nacional de Comunicação e Educação Ambiental. Diretrizes para Estratégia Nacional de Comunicação Ambiental em Unidades de Conservação. Brasília: Ministério do Meio Ambiente, 2011.

4. SANTOS, Maria Nunes dos. Educar no ambiente, construção do olhar geocientífico e cidadania. São Paulo: Annablume, 2011.

O livro divide-se em cinco capítulos: 1o "O ensino das geociências"; 2o "As geociências e a formação de professores"; 3 "O projeto escolar e o estudo do ambiente"; $4^{\circ}$ "Ensino em geociências e educação ambiental: a construção do 'olhar geocientífico' na escola"; 5o "Projetos escolares de educação ambiental".

$\mathrm{O}$ trabalho não se volta explicitamente para a área da Comunicação. Deixa, contudo, antever que a comunicação deve ser incluída no tratamento da educação ambiental enquanto um dos possíveis níveis de abordagem do fato social. Nesse sentido, no âmbito do que se entende por pedagogia de projetos, a leitura da obra propicia elementos para a implementação, em estruturas complexas como as redes escolares, daquilo que as políticas públicas (em especial a proposta pelo Ministério do Meio Ambiente) denominam educomunicação socioambiental. 